\title{
The Mechanical Fracture of a Railway Bogie under Cyclic Loading by Ansys
}

\author{
Redouan Zellagui ${ }^{1, a}$, Ahmed Bellaouar ${ }^{1}$ and Mohammed Lachi $^{2}$ \\ ${ }^{1}$ Transportation Engineering and Environment Laboratory, University of Constantine 1, Algeria \\ ${ }^{2}$ University of Reims Champagne Ardenne France
}

\begin{abstract}
The main objective this study has been to modeling a train bogie in order to highlight some flaws. Indeed, during the operation, premature deterioration of the bogie axles was observed. The purpose of this model is to present a numerical model to predict the mechanical behavior under different cyclic form of stress. The numeric and geometric model will be directed by Ansys software.
\end{abstract}

\section{Introduction}

The mechanical power transmission systems must be more reliable, this trend is true for all transport systems, handling equipment etc. The consulting firms are sometimes faced with design and integration problems; they operate increasingly the results of numerical models. Today, we talk about digital model of global mechanical behavior. Numerical modeling has become an essential tool to gain more time and to facilitate the shaping of complex systems and predicting models in order to achieve optimal designs. The work has been initiated according to the findings made at the railway of Constantine where premature cracks in the chassis have been noted. The studied element is the train bogie where some elements, such as axes, showed cracks after a relatively short operating time. The bogie is an important mechanism composed of elements that contribute to the transmission of engine torque as well as to the transmission of the forces exerted by the gear to the wheels. From a work perspective, the bogie comprises several organs, the main ones: the chassis, the two sets (axles and wheels) and the three sets (spring, boxes, axles and brake discs). Our approach is to determine the stress field according to a dynamic loading in order to predict the critical areas or regions. Figure 1, shows the damage portion of the frame removed from the site following an accident due mainly to a sudden failure problem.

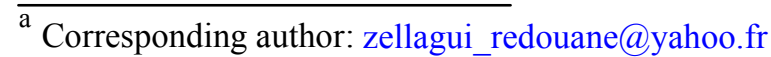

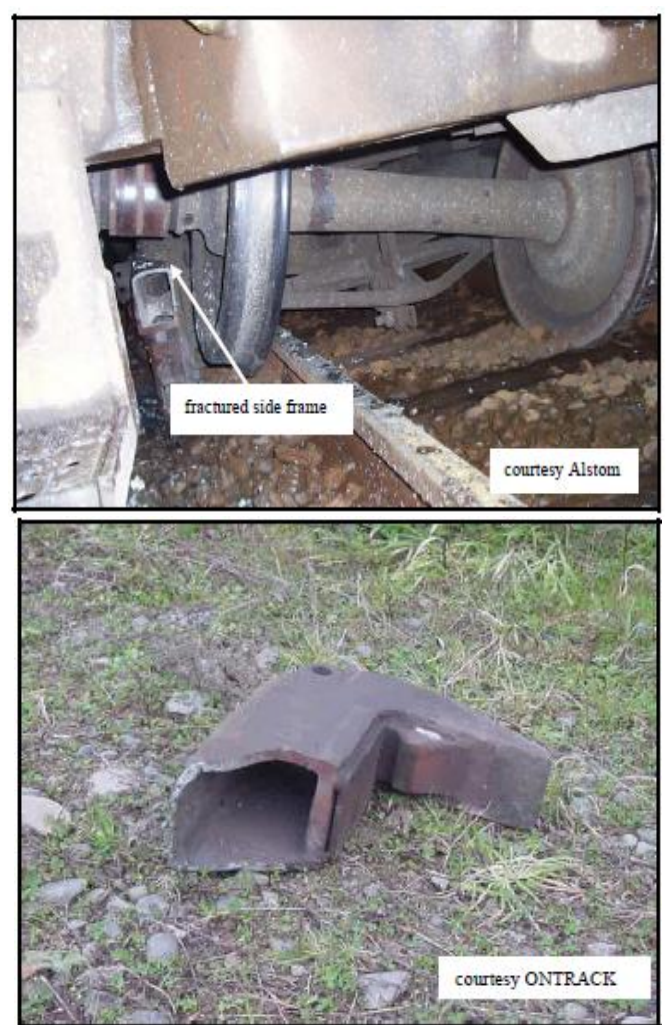

Fig 1: Fractured bogie.

\section{Fracture mode}

Three linearly independent cracking modes are used in fracture mechanics. These load types are categorized as Mode I, II, or III as shown in the figure. Mode I, shown to the left, is an opening (tensile) mode where the crack surfaces move directly apart. Mode II is a sliding (inplane shear) mode where the crack surfaces slide over one another in a direction perpendicular to the leading 
edge of the crack. Mode III is a tearing (antiplane shear) mode where the crack surfaces move relative to one another and parallel to the leading edge of the crack. Mode $\mathrm{I}$ is the most common load type encountered in engineering design.

Different subscripts are used to designate the stress intensity factor for the three different modes. The stress intensity factor for mode I am designated $K_{I}$ and applied to the crack opening mode. The mode II stress intensity factor $K_{I I}$, applies to the crack sliding mode and the mode III stress intensity factor $K_{I I I}$, applies to the tearing mode. These factors are formally defined as:

$\sigma_{i j}(r, \theta)=\frac{1}{\sqrt{2 \pi r}}\left(K_{I} \cdot f_{i j}^{(I)}(\theta)+K_{I I} \cdot f_{i j}^{(I I)}(\theta)+\right.$
$\left.K_{I I I} \cdot f_{i j}^{(I I I)}(\theta)\right)$

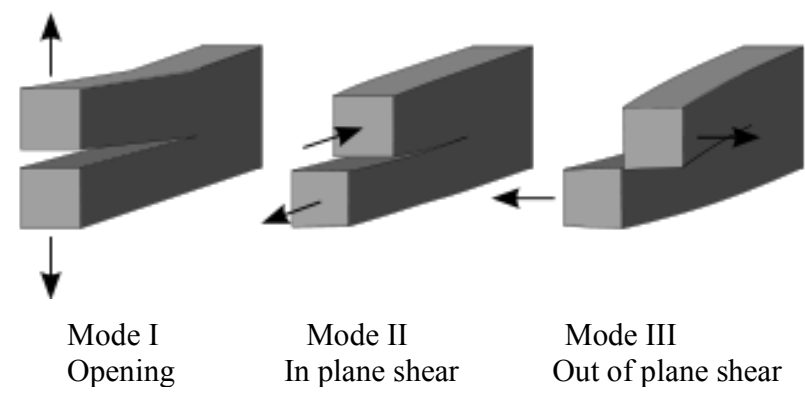

Fig2: Three fracture modes.

Due to its predominance in this situation, mode1 has been considered. The governing equations of stresses and displacements are:

$$
\left\{\begin{array}{l}
\sigma_{11}=\frac{\mathrm{K}_{\mathrm{I}}}{\sqrt{2 \pi \mathrm{r}}} \cos \frac{\theta}{2}\left(1-\sin \frac{\theta}{2} \sin \frac{3 \theta}{2}\right) \\
\sigma_{22}=\frac{\mathrm{K}_{\mathrm{I}}}{\sqrt{2 \pi \mathrm{r}}} \cos \frac{\theta}{2}\left(1+\sin \frac{\theta}{2} \sin \frac{3 \theta}{2}\right) \\
(2) \\
\sigma_{12}=\frac{\mathrm{K}_{\mathrm{I}}}{\sqrt{2 \pi \mathrm{r}}} \cos \frac{\theta}{2} \sin \frac{\theta}{2} \sin \frac{3 \theta}{2} \\
\left.\mathrm{~K}_{\mathrm{I}}=\lim _{\mathrm{r} \rightarrow 0} \sqrt{2 \pi \mathrm{r}} \sigma_{22} \text { (r. } 0\right)
\end{array}\right.
$$$$
\text { (3) }
$$

The analytical model is governed by the following equations which show the stress state of the chassis:

\section{Exceptional Loads}

Vertical forces (Applied to each side frame):

$$
\mathrm{F}_{\mathrm{z} 1 \max }=\mathrm{F}_{\mathrm{z} 2 \text { max }}=\frac{\mathrm{F}_{\mathrm{z} \max }}{2}=\frac{1.4 * \mathrm{~g}}{4}\left(\mathrm{M}_{\mathrm{v}}+\mathrm{P}_{1}-2 \mathrm{~m}^{+}\right)
$$

Transverse forces (applied to each axle):

$\mathrm{F}_{\mathrm{y} 1 \max }=\mathrm{F}_{\mathrm{y} 2 \max }=\frac{\mathrm{F}_{\mathrm{y} \max }}{2}=10^{4}+\frac{\left(\mathrm{M}_{\mathrm{v}}+\mathrm{P}_{1}\right) \mathrm{g}}{12}$
Longitudinal shear forces (applied to each wheel and in the opposite sense on the opposite sides of the bogie frame):

$\mathrm{F}_{\mathrm{x} 1 \max }=0.1 \mathrm{x}\left(\mathrm{F}_{\mathrm{z}}+\mathrm{m}^{+} \mathrm{g}\right)$

\section{Normal service loads}

Vertical forces (Applied to each side frame):

$\mathrm{F}_{\mathrm{z} 1}=\mathrm{F}_{\mathrm{z} 2}=\frac{\mathrm{F}_{\mathrm{z}}}{2}=\frac{\mathrm{g}}{4}\left(\mathrm{M}_{\mathrm{v}}+1.2 \mathrm{P}_{1}-2 \mathrm{~m}^{+}\right)$

Transverse forces (applied to each axle):

$\mathrm{F}_{\mathrm{y} 1}=\mathrm{F}_{\mathrm{y} 2}=\frac{\mathrm{F}_{\mathrm{y}}}{2}=\frac{\mathrm{F}_{\mathrm{z}}+\mathrm{m}^{+} \mathrm{g}}{8}$

Longitudinal shear forces (applied to each wheel and in the opposite sense on the opposite sides of the bogie frame):

$\mathrm{F}_{\mathrm{x} 1 \max }=0.05 \mathrm{x}\left(\mathrm{F}_{\mathrm{z}}+\mathrm{m}^{+} \mathrm{g}\right)$

The calculations are done according to the information and conditions given by the clients are as follows, the train characteristics are listed in the table 1.

Table1. Train characteristics [2]

\begin{tabular}{|c|c|}
\hline The train Characteristics & Value \\
\hline $\mathrm{m}^{+}$ & $4000 \mathrm{~kg}$ \\
\hline $\mathrm{P}_{1}$ & $5000 \mathrm{~kg}$ \\
\hline $\mathrm{M}_{\mathrm{v}}$ & $35000 \mathrm{~kg}$ \\
\hline $\mathrm{g}$ & $9.81 \mathrm{~m} / \mathrm{s}^{2}$ \\
\hline
\end{tabular}

\section{Numerical Model}

In order to analyze the mechanical behavior of the chassis, a general model using Ansys software was realized. The applied mechanical properties are listed in Table 2. According to solicitations previously defined, the critical areas of the chassis are defined.

Table 2. Mechanical properties.

\begin{tabular}{|c|c|}
\hline Mechanical properties & Value \\
\hline Elastic Modulus & $206[\mathrm{GPa}]$ \\
\hline Yield Strength & $345[\mathrm{MPa}]$ \\
\hline Poissons Ratio & 0.3 \\
\hline Density & $7850\left[\mathrm{Kg} / \mathrm{m}^{2}\right]$ \\
\hline
\end{tabular}

The bogie frame is supported at 4 axle boxes. FE model of the locomotive bogie frame is shown in Fig 3. The bogie frame structure is modeled with solid, spring and rigid elements.

The analysis model of the chassis consists of 110453 nodes and 90265 elements. In this model, $\mathrm{x}$-axis is 
longitudinal, y-axis is transverse and z-axis is vertical direction respectively.

Figure 4 shows the numerical model and the possible loading cases so that to make a comprehensive study on the mechanical behavior of the chassis using the Ansys software.

In our study we supposed the vertical loads which are harmonic with the frequency $\mathrm{f}=0.2 \mathrm{~Hz}$ and its form is $F_{z 1}=F_{z 2}=\frac{F_{z}}{2} \sin (\omega t)$

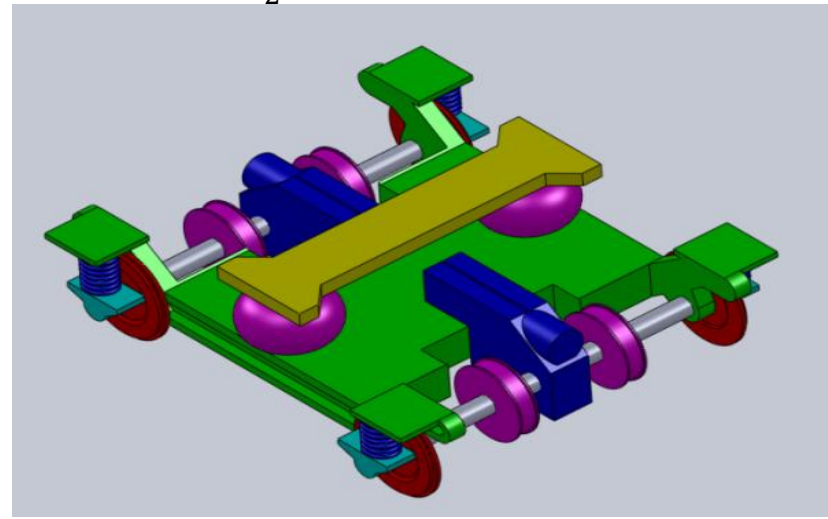

Figure 3. Geometric Model of the bogie.

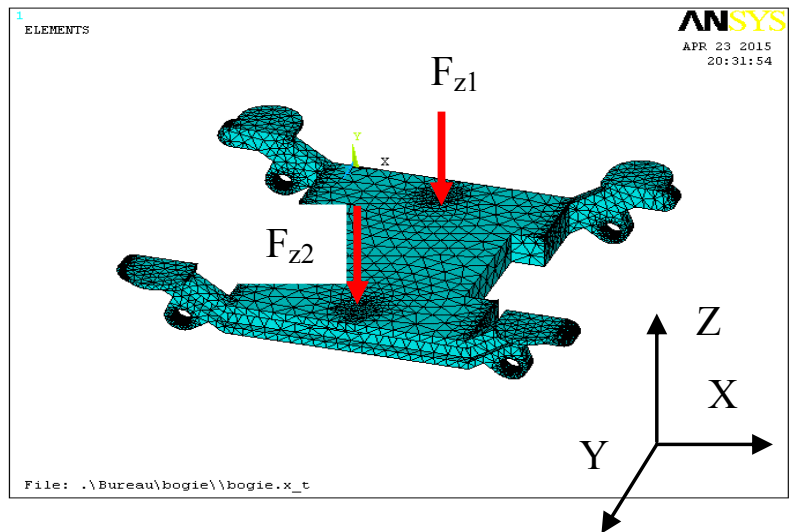

Figure 4. chassis loading.

\section{Discussion of Results}

Figures 5 and 6 shows the instant variation constraints. The danger zone of the frame is located on both sides left and right. The maximum value is obtained at the node 172 with a value of $80 \mathrm{MPa}$. Figure 7 shows exactly the area where the break occurred.

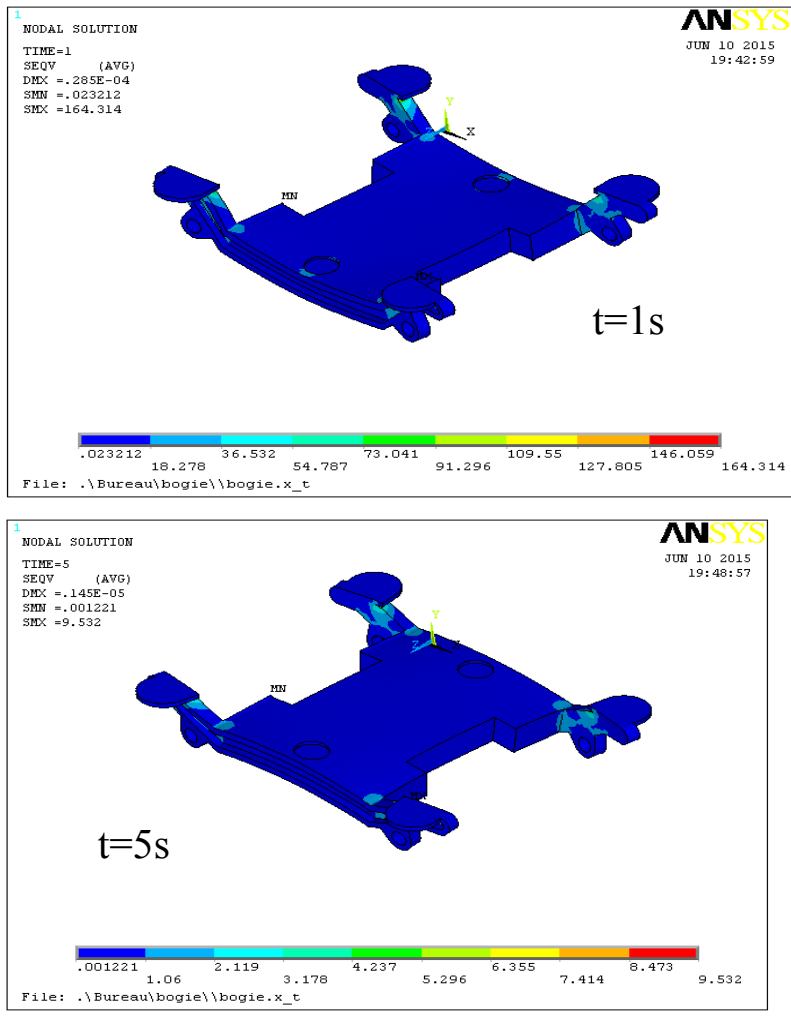

Figure 5. Von Misses Stress.
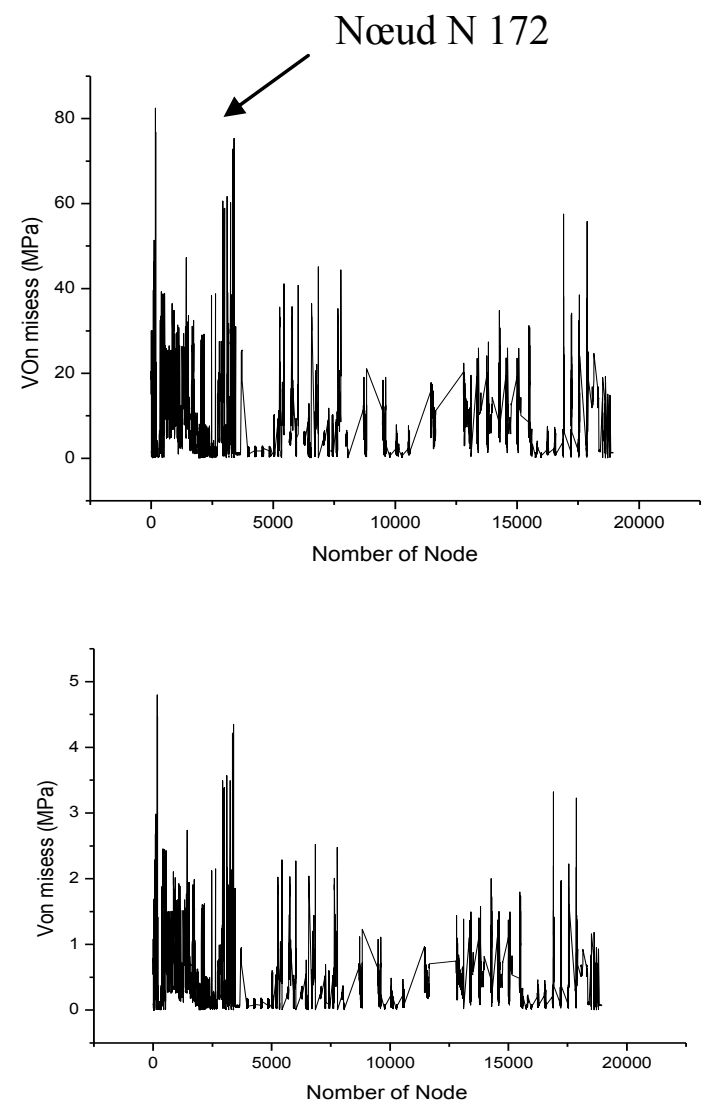

Figure 6. Nodal solution of Von misses stress 


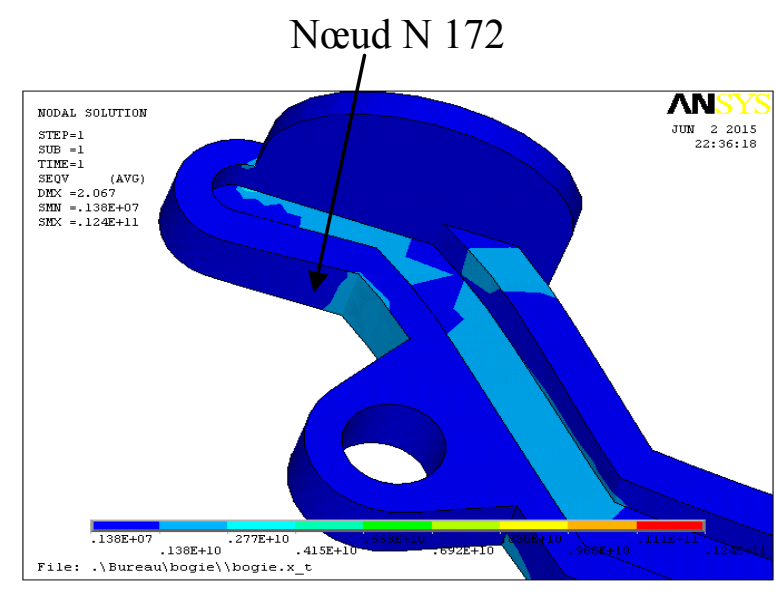

Figure 7. Distribution of stresses in the critical area.

Figures 8 and 9 show the displacements along $\mathrm{Y}$ and $Z$ respectively that have been recorded according to the load condition which is presented in Figure 4. Figure 8 shows that the displacement field varies alternately between the center and the ends of the frame to the maximum values respectively 0.145 and $0.301 * 10-3 *$ $10-3 \mathrm{~mm}$. Figure 9 shows that the displacements are also alternating according to $\mathrm{Z}$ direction what is in very good agreement with the initial loading conditions.

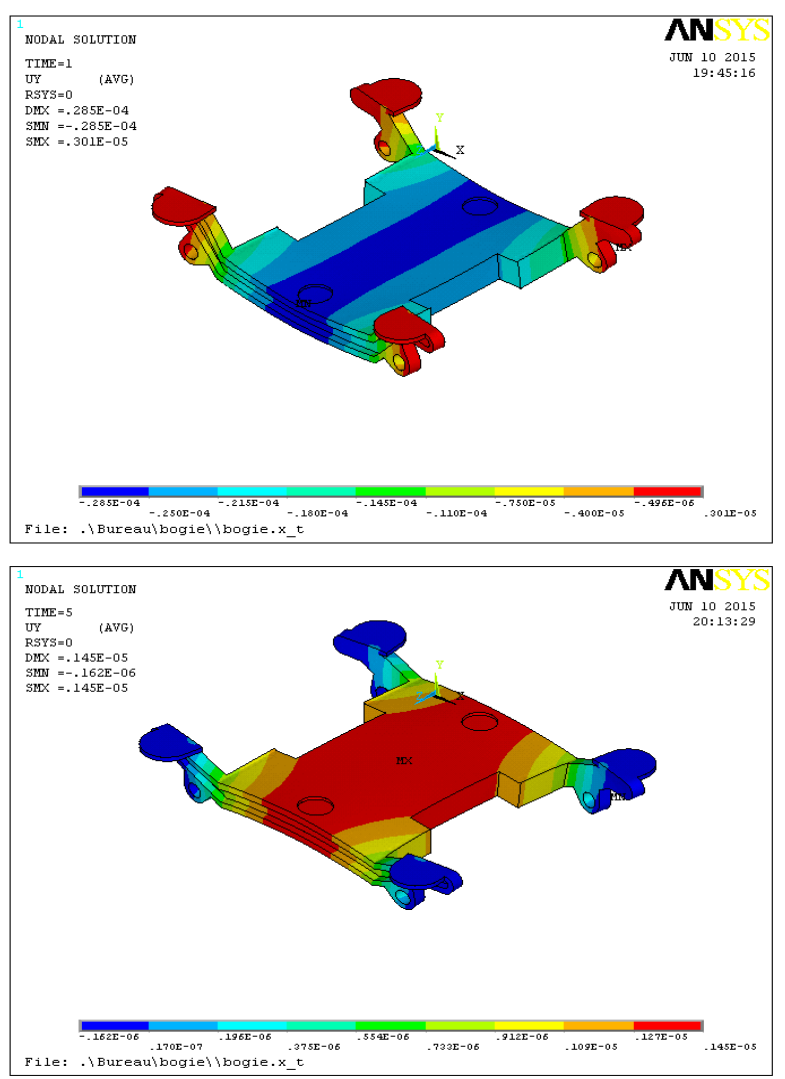

Figure 8. Evolution of displacement along Y.

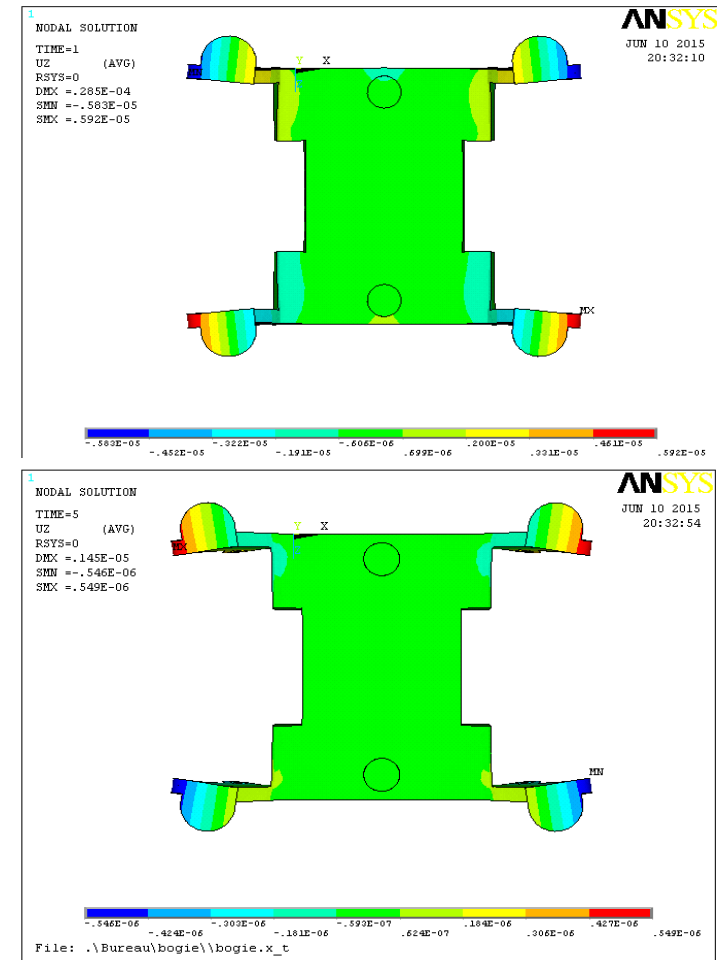

Figure 9. Evolution of displacement in Z.

The maximum value of the displacement has been reached at the 3319 node along the $\mathrm{Z}$ axis. It can be noticed that there is a decreasing alternating trend equal to $0.0005 \mathrm{~mm}$ in each period.

After locating areas that may be the cause of the cracks observed on the chassis, we proceeded with the modeling of a rectangular dish of the critical section of the chassis as a two-dimensional structure $\left(50 * 100 \mathrm{~mm}^{2}\right)$ with a crack of $5 \mathrm{~mm}$ (plane deformation state) shown in figure 10 with the maximum stress previously found. Our objective is to determine the variation of the stress intensity factor $(\mathrm{KI})$.

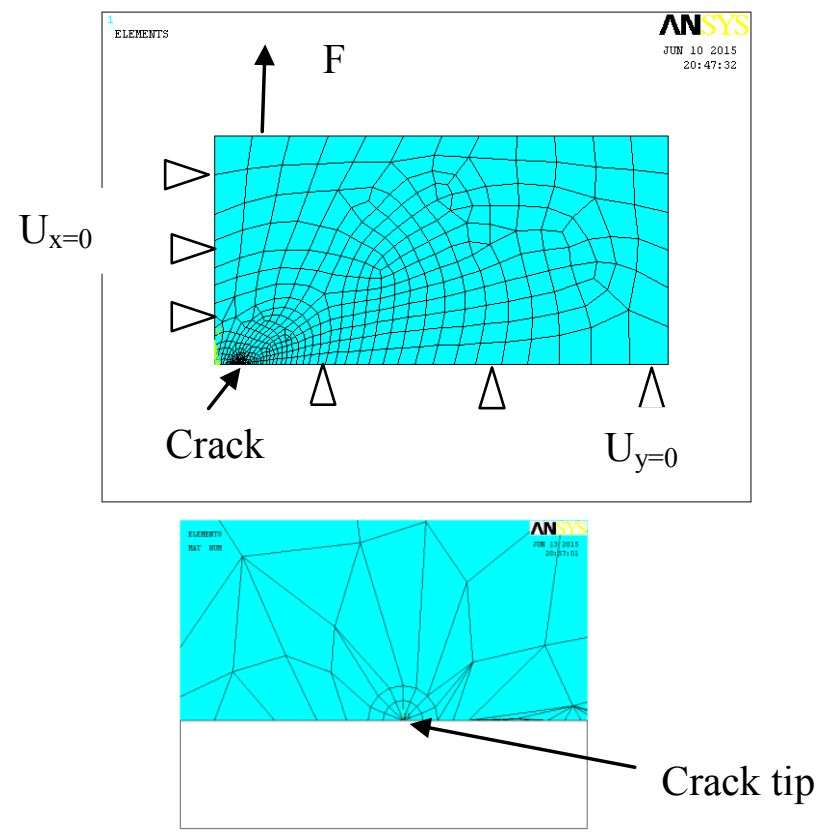

Figure 10. Crack in the critical area. 


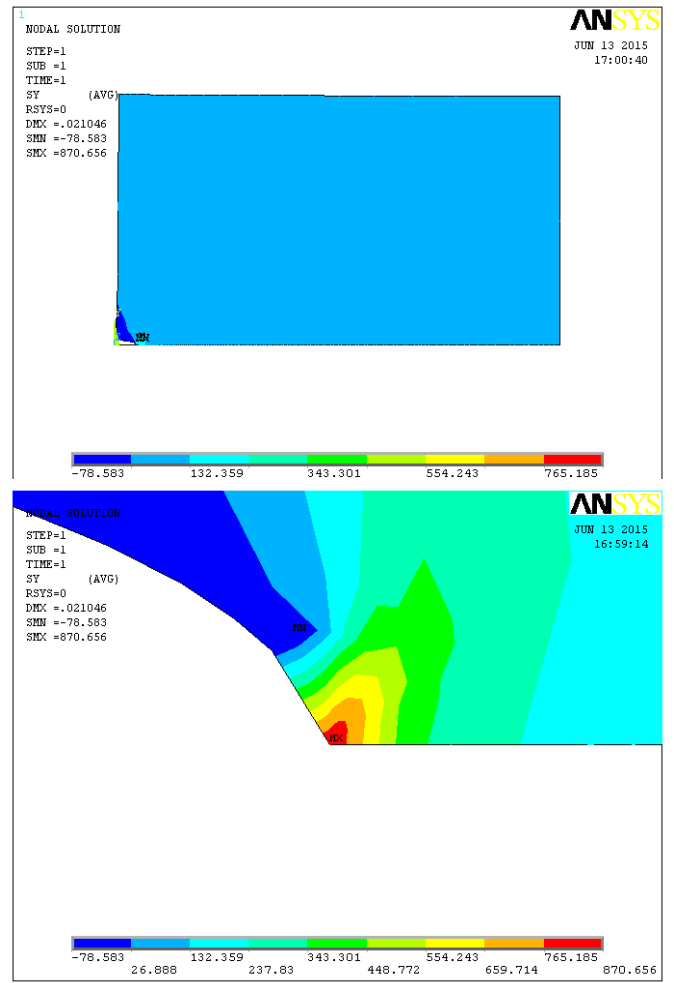

Figure 11. Stress in crack tip

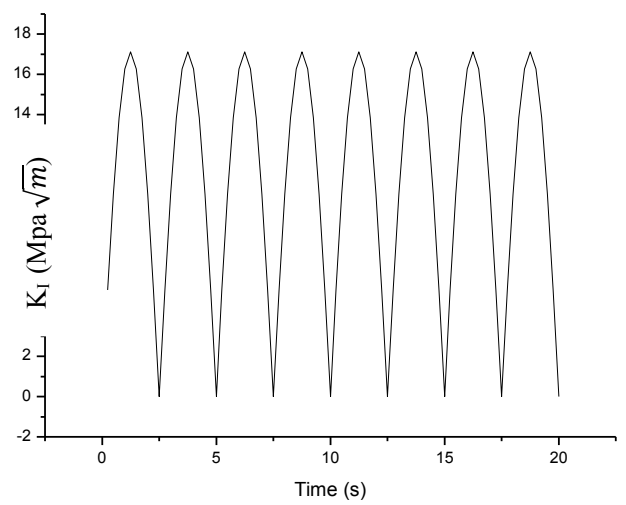

Figure12. Variation of stress intensity factor

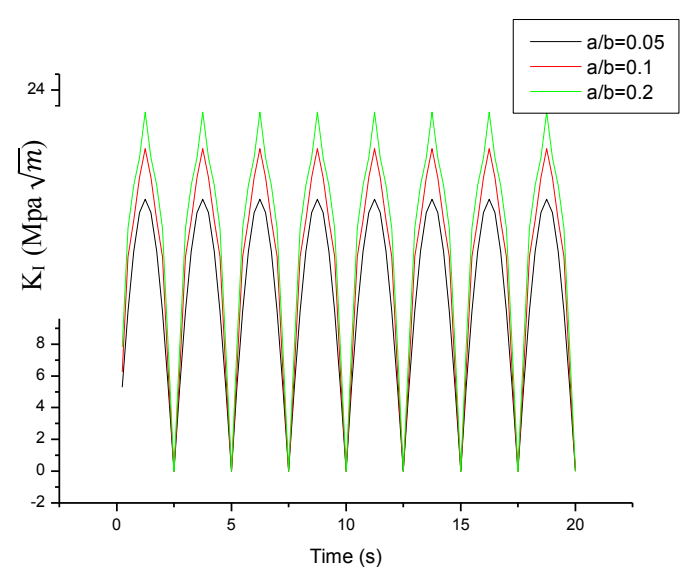

Figure13. Variation of stress intensity factor.

Figure 13 expresses the variation of the intensity factor for both crack $(5 \mathrm{~mm}, 10 \mathrm{~mm}$ and $20 \mathrm{~mm})$. One notices the difference in the case of the crack with the highest value.

\section{Conclusion}

The modeling considered has allowed building a digital model of the chassis frame in order to locate highly loaded areas according to dynamic stress. The results show the variation of the stress concentration factor in the assumed critical area. The cracked area determined according to the model is in good agreement with the actually damaged area. The maximum value of the stress is $80 \mathrm{MPa}$ located at node 172 of the model. The stress concentration factor alternately changing over time and increases as a function of the crack length. The critical area (cracked) should be instantly controlled to prevent any disaster on the chassis.

\section{References}

1. Campedlli, J., Modélisation globale statique des systèmes mécaniques hyperstatiques pré-charges (application a un bogie de train), 2005.

2. Rice, J. Rosengren, R., Plain strain deformation near a crack-tip in a power-law hardening material, 1968.

3. Smith, R., Hillmansen, S,. Monitoring Fatigue in Railway Axles, 2001.

4. Carpinteri, R. Brighenti, A. Spagnoli. Fatigue growth simulation of part through flaws in thick walled pipes under rotary bending, 2000.

5. H. Weixing. Calculation and analysis of expanding fatigue cracks on axle, 1992.

6. Bower. The influence of crack face friction and trapped fluid in surface initiated rolling contact fatigue cracks, 1988.

7. Y. Shimokawa, M. mizuno. Development of the New Concept Steering Bogie, 2013.

8. F. dikmen, M. bayraktar, R.guclu Dynamic analysis of rail vehicle axle. 2013.

9. J. Yang1, J. Wang1, X. Li. Fatigue Analysis for Bogie Frame of Beijing Subway Vehicle under Overload Situation. 2014. 